\title{
Vaginal versus Intramuscular Progesterone in the Prevention of Recurrent Preterm Labour
}

\author{
Mahmoud kamel Harb, ${ }^{1}$ M.B.B. Ch, Ashraf Hamdy Mohamed, ${ }^{1}$ M.D, Adel Aly Elboghdady, ${ }^{1}$ M.D.
}

\author{
* Corresponding Author: \\ Mahmoud Kamel Harb \\ dockamel184@gmail.com
}

Received for publication March 10, 2020; Accepted May 6, 2021;

Published online May 6, 2021.

\section{Copyright 2020 The Authors published by Al-Azhar University, Faculty of Medicine, Cairo, Egypt. All rights reserved. This an open-access article distributed under the legal terms, where it is permissible to download and share the work provided it is properly cited. The work cannot be changed in any way or used commercially. \\ doi: 10.21608/aimj.2021.65704.1426. \\ ${ }^{1}$ Obstetrics and Gynecology Department, Faculty of Medicine, Al-Azhar University, Cairo, Egypt.}

\begin{abstract}
Background: Preterm Labour is characterized as the occurrence of uterine contractions of sufficient frequency and intensity to affect the cervix's progressive effacement and dilation before to term gestation.

Aim of the study: Comparison of vaginal and intramuscular progesterone to prevent premature labor in women with a history of spontaneous preterm labor recurrence.

Patients and Methods: From April to November 2020, Al-Hussein Hospital, Al-Azhar University, conducted a comparative clinical trial study. In this research, one hundred (100) pregnant women have been selected and divided into 3 groups (vaginal progesterone group (A), intramuscular progesterone group (B), and control group (C)) with a history of prior spontaneous premature labor.

Results: Statistically significant differences were found among the progesterone groups and the control group with respect to NICU admissions, with a higher percentage of NICU admission among the control group (63.3\%) compared to the progesterone groups $(25.2 \%)$. There were also statistically significant differences among the vaginal progesterone group \& the intramuscular progesterone group as regards NICU admission with higher percentage of NICU admission among the intramuscular progesterone group (40\%) compared to the vaginal progesterone group (11.4\%).

Conclusion: In ladies who have had repeated spontaneous preterm labor, progesterone used prophylactically decreases the rate of premature labor, lowers the frequency of uterine contractions, and enhances the symptoms of preterm labor. In women at risk for PTL, vaginally administered progesterone was almost as effective as intramuscular progesterone in preventing PTL, with the vaginal route having a superior impact.
\end{abstract}

Keywords: progesterone; prevention; preterm; labour.

Disclosure: The authors have no financial interest to declare in relation to the content of this article. The Article Processing Charge was paid for by the authors.

Authorship: All authors have a substantial contribution to the article.

\section{INTRODUCTION}

Preterm labour (PTL) is the major reason of perinatal and neonatal mortality and morbidity, which is closely related to developmental and neurological disorders later in life. ${ }^{1}$

The occurrence of this issue is growing and is estimated to be $15 \%$ of pregnancy in the developed world. Preventing it is also regarded a major challenge for obstetricians. ${ }^{2}$

Survival of the preterm infant is directly related to gestational age at delivery; Survival increases from less than $50 \%$ before 24 weeks to more than $95 \%$ by 33 weeks' gestation and a corresponding inverse association exists among the risk of serious disability in survivors and the pregnancy age at birth. ${ }^{3}$ 
and timing of initiation of therapy in risky women to avoid PTL. ${ }^{7}$

The purpose of this research has been to compare the efficacy of vaginal and intramuscular progesterone in preventing Preterm labour and on serum progesterone level in patients with history of recurrent spontaneous preterm labour.

\section{PATIENTS AND METHODS}

This comparative clinical trial study was carried out from April 2020 to November 2020 at Al-Hussein Hospital, Al-Azhar University. One hundred (100) of pregnant women have been selected and divided into 3 groups (vaginal progesterone group (A), intramuscular progesterone group (B) and control group (C)) with a history of prior spontaneous premature labor.

The study included women selected for this study who were sought to be at high risk for preterm labor have all the following criteria. singleton pregnancy, gestational Age of 20 to 24 weeks and patient with ast history of one or more spontaneous preterm labor.

While patients with multi-fetal pregnancy, history of ante partum PROM, cervical Incompetence or current cervical cerclage, known fetal anomaly, hypertension requiring medications, progesterone or Heparin treatment in current pregnancy or history of thrombo-embolic disorders, known allergy to progesterone, known liver disease and established preterm labor were excluded from the study.

All women were subjected to:

A. At the first antenatal visit; Full History taking, complete general and abdominal examination and Routine laboratory investigations (full labs). Estimation of gestational age; Estimation based on the last menstruation cycle and ultrasonography up to 12 weeks or two congruent scans among 12 and 24 weeks. Routine trans-abdominal ultrasound to assess the gestational age and to exclude fetal anomalies. Trans-vaginal ultrasound every four weeks to assess cervical length and funneling, Prophylactic medical treatment; All pregnant women in the study received prophylactic medical treatment for bacterial vaginosis and Chlamydial infection in the form of Azithromycin tablets $500 \mathrm{mg}$. orally once daily for 3 days and Metronidazole tablets $250 \mathrm{mg}$. three times per day for 7 days. Medications were given just before starting progesterone therapy. Treatment was started at 20-24 weeks gestation; The first 35 patients (Group A) will be given micronized progesterone tablets vaginally $200 \mathrm{mg}$ twice daily and the second 35 patients (Group B) will be given 100mg of intramuscular progesterone every third day While the third group (Group C) included 30 women who did not receive any PTL prevention progesterone and settled in the control group. Treatment will be continued until completed 36 weeks gestation or until occurrence of PROM or delivery. All women were advised about the benefit of the drug used and a written approval of the study was taken from each woman. A schedule of next visits was given to each woman. The fetal middle cerebral artery, umbilical artery and uterine artery will be examined by Doppler prior and one week following progesterone administration, progesterone will be continued until 36 weeks of pregnancy or childbirth. ${ }^{8}$ Serum progesterone monitoring will be done before progesterone administration and in the late second/early third trimester.

B. At the follow up visits: For 28 to 36 weeks of pregnancy, all pregnant women in the left lateral position underwent uterine contraction tracking with an external tocodynamomerer every other week for 60 min with an external monitor.

We determine the duration of contractions. Before the 30th week of pregnancy, four or more contractions per hour were deemed positive and after the 30th week, six or more contractions per hour were deemed positive. All pregnant women were questioned whether they had encountered any symptoms of preterm labor, such as heaviness, cramping, abdominal colic, or a sudden flow of fluid.

Statistical analysis:

The findings are represented as mean \pm standard deviation or number (percent). If significant findings were reported, a one-way ANOVA with LSD test was used to compare numerical data in three studied groups. A Chi square test was used to compare categorical results. For data processing, the SPSS computer software (version 19 windows) was used. Significant was defined as a $\mathrm{P}$ value of less than or equal to 0.05 , and highly significant as a $\mathrm{P}$ value of less than 0.01 .

Outcome data were available for 100 women, 35 women in the vaginal progesterone group (Group A), 35 women in the intramuscular progesterone group (Group B) \& 30 women in the control group (Group C).

\section{RESULTS}

There are no statistically significant differences among all groups with respect to age, parity and number of previous preterm labors (Table 1 ).

There are no statistically significant differences among all groups with respect to Mode of delivery (Table 2).

There were statistically significant differences among the progesterone groups \& the control group with respect to NICU admission with higher percentage of NICU admission among the control group (63.3\%) compared to the progesterone groups (25.2\%)

Also, there were statistically significant differences among the vaginal progesterone group \& the intramuscular progesterone group as regards NICU 
admission with higher percentage of NICU admission among the intramuscular progesterone group (40\%) compared to the vaginal progesterone group (11.4\%) (Table 3).

There were statistically significant differences among both progesterone groups pre and post progesterone administration as regards mean values of MCA RI with higher MCA RI before progesterone administration (0.86) than after (0.79) (Table 4).

There were no statistically significant differences among both progesterone groups before and after progesterone administration as regards mean values of UA RI (Table 5).

\begin{tabular}{|c|c|c|c|c|}
\hline & Control $(n=30)$ & $\begin{array}{ll}\text { Vaginal } & (\mathrm{n}= \\
35) & \\
\end{array}$ & Intramuscular(n=35) & P value \\
\hline Age (yrs.) & $26.80 \pm 4.26$ & $28.71 \pm 4.09$ & $28.23 \pm 4.75$ & $0.200(\mathrm{NS})$ \\
\hline Parity & $3.10 \pm 0.85$ & $3.14 \pm 0.60$ & $2.91 \pm 0.56$ & $0.326(\mathrm{NS})$ \\
\hline No. of PLT & $2.40 \pm 0.50$ & $2.49 \pm 0.51$ & $2.51 \pm 0.51$ & 0.645 (NS) \\
\hline
\end{tabular}

Table 1: Demographic features of different studied groups.( Data is represented as mean \pm SD; NS $=p>0.05=$ not significant)

\begin{tabular}{|l|l|l|l|l|}
\hline & Control $(\mathrm{n}=30)$ & Vaginal(n= 35) & Intramuscular(n=35) & P value \\
\cline { 1 - 4 } CS & $10(33.3 \%)$ & $12(34.3 \%)$ & $12(34.3 \%)$ & \multirow{2}{*}{$0.996(\mathrm{NS})$} \\
\hline Vaginal & $20(66.7 \%)$ & $23(65.7 \%)$ & $23(65.7 \%)$ & \\
\hline
\end{tabular}

Table 2: Mode of delivery in different studied groups.( Data is represented as number (\%).; NS= $\mathrm{p}>0.05=$ not significant)

\begin{tabular}{|l|l|l|l|l|}
\hline & Control $(\mathrm{n}=30)$ & Vaginal $(\mathrm{n}=35)$ & Intramuscular(n= 35) & \multirow{2}{*}{ P value } \\
\hline No & $11(36.7 \%)$ & $31(88.6 \%)$ & $21(60.0 \%)$ & \multirow{2}{*}{$0.001^{* *}$} \\
\hline Yes & $19(63.3 \%)$ & $4(11.4 \%)$ & $14(40.0 \%)$ & \\
\hline
\end{tabular}

Table 3: The admission of the Neonatal Intensive Care Unit (NICU) in different studied groups..( Data is represented as number (\%).; $\mathrm{P}<0.01=$ highly significant)

\begin{tabular}{|l|l|l|l|l|}
\hline & Control $(\mathrm{n}=30)$ & Vaginal $(\mathrm{n}=35)$ & Intramuscular(n=35) & P value \\
\hline Before & $0.88 \pm 0.03$ & $0.87 \pm 0.02$ & $0.85 \pm 0.03^{\text {aa bb }}$ & $0.001^{* *}$ \\
\hline After & $0.88 \pm 0.04$ & $0.79 \pm 0.02^{\text {aa }}$ & $0.79 \pm 0.02^{\text {aa }}$ & $0.001^{* *}$ \\
\hline P value & $0.580(\mathrm{NS})$ & $0.001^{* *}$ & $0.001^{* *}$ & \\
\hline
\end{tabular}

Table 4: Comparison among average values of MCA RI calculated pre and post progesterone administration in different studied groups .( Data is represented as mean \pm SD; NS $=p>0.05=$ not significant; ${ }^{* *} \mathrm{p}<0.01=$ highly significant; aa $\mathrm{p}<0.01$ relative to control group)

\begin{tabular}{|l|l|l|l|c|}
\hline & Control $(\mathrm{n}=\mathbf{3 0})$ & \multicolumn{1}{|c|}{ Vaginal(n= 35) } & Intramuscular(n= 35) & P value \\
\hline Before & $\mathbf{0 . 7 5} \pm \mathbf{0 . 0 2}$ & $0.75 \pm 0.03$ & $0.73 \pm 0.03$ & 0.067 (NS) \\
\hline After & $\mathbf{0 . 7 5} \pm \mathbf{0 . 0 2}$ & $\mathbf{0 . 7 5} \pm \mathbf{0 . 0 3}$ & $\mathbf{0 . 7 3} \pm 0.03$ & $\mathbf{0 . 0 6 7}$ (NS) \\
\hline P value & --- & --- & --- & \\
\hline
\end{tabular}

Table 5: Comparison among average values of UA RI calculated pre and post progesterone administration in different studied groups .( Data is represented as mean \pm SD; NS= p>0.05= not significant).

\section{DISCUSSION}

Progesterone is a steroid hormone that helps sustain pregnancy. Progesterone elimination, or obstruction of its receptors, reliably finishes pregnancy at all stages of pregnancy, and declining levels precipitate natural labor in several non-human species. ${ }^{6}$

Different forms and doses of progesterone are examined in several earlier studies in decreasing PTL, however so far there are not adequate information comparing styles, doses, methods of administration and period of progesterone starting. ${ }^{7}$

The gestational age was estimated based of the last cycle of menstruation, and ultra-sonographic examination. Medications started at 24 weeks of gestation and stopped at the end of 36 weeks of gestation and preceded by prophylactic medical treatment for bacterial vaginosis.

There was no statistically significant variation in the age, parity, mode of delivery and number of prior preterm labors among the three groups. ${ }^{9}$

There is a great reason to prescribe $200 \mathrm{mg}$ of vaginal progesterone per day to prevent PTL in ladies with a $15 \mathrm{~mm}$ short cervix identified by the TVS scan at 22-26 weeks. ${ }^{10}$ 
In the prevention of recurrent PTL in women with previous PTL, IM $17 \alpha$ hydroxyl progesterone 250 mg once weekly or vaginal progesterone $100 \mathrm{mg}$ daily has been prescribed. When it comes to beginning progesterone to avoid PTL, there is no indication that starting before 20 weeks or using higher doses is beneficial. ${ }^{\mathbf{1 1}}$

Study by O'Brien et al. ${ }^{12}$, on the other hand, stated that vaginal progesterone may not minimize the incidence of early PTL, neonatal mortality or morbidity and that it can be clarified by conducting a single-risk factor (previous PTL) study in women, taking into account the primary outcomes of PTL $<32$ weeks, by using progesterone at a dose of $90 \mathrm{mg}$ and in vaginal gel form.

In this research, the average birth weight and average GA at delivery were substantially higher in the progesterone-treated groups relative to the control group, whether vaginally or I.M. ${ }^{13,14}$

From the other hand, two other researches indicated that in ladies who obtained progesterone, but without shifts in neonatal mortality, the ratio of neonatal admissions to Intensive care unit became significantly lower. ${ }^{15,16}$

A substantial decline in MCA-PI and RI has been documented in this research without substantial changes in UA Doppler indexes with vaginally administered progesterone . ${ }^{17}$

We found a substantial decline in Ut, in comparison to the same researchers. Following administration of vaginal progesterone, A-RI and PI may have clarified the disparity in timing of Doppler re-examination (In their research, 24 hours after the first dose of vaginal progesterone was given, and in this research, one week after vaginal progesterone was given), including cases of GA 24-32 weeks with effects of various gestational ages on Doppler examination.

As regards serum progesterone level before and after progesterone administration, our study revealed that it was below the normal level at 24wks measuring approximately 50ng/ml compared to the average normal level at this gestational age $73 \mathrm{ng} / \mathrm{ml}$.

Six weeks after progesterone administration (at thirty weeks gestation), serum progesterone level was approaching the average normal level at this age $(100 \mathrm{ng} / \mathrm{ml})$ in both progesterone groups with higher average level in the vaginal group $(100 \mathrm{ng} / \mathrm{ml})$ than the intramuscular group $(92.9 \mathrm{ng} / \mathrm{ml})$ while in the control group, serum progesterone level was still away from the average normal levels at this gestational age $(82 \mathrm{ng} / \mathrm{ml})$ augmenting the need for progesterone support in this high risk population with the need for further studies regarding when to start treatment, mode and dose of progesterone.

The short-term impact of progesterone has been studied here; however the long-term impact has not been examined as in some instances, drugs other than progesterone have been obtained like betamethasone and some vasodilator-effect tocolytic medicines.

Aside from a single retrospective research 18 that found that the occurrence of gestational diabetes mellitus was $12.9 \%$ in ladies treated with I.M 17 alpha hydroxyl progesterone $250 \mathrm{mg}$ weekly (557 instances) relative to $4.9 \%$ in control instances, no evidence from RCTs and other research suggest that progesterone usage in the avoidance of PTL is not secure (1524 instances), because of the limited number of instances and the advocacy of more largescale studies, safety cannot be confirmed in this research.

\section{CONCLUSION}

In women who have had repeated spontaneous preterm labor, progesterone used prophylactically decreases the rate of premature labor, lengthens gestational age at delivery, decreases the frequency of uterine contractions, and enhances symptoms of preterm labor.

In ladies at risk for PTL, vaginally administered progesterone became almost as successful as intramuscular progesterone in preventing PTL, with the vaginal route having a superior impact, and both were correlated with substantial reductions in fetal MCA-PI and RI, however vaginal progesterone only had a substantial reductions in uterine artery RI and PI.

\section{REFERENCES}

1. Manuck TA, Rice MM, Bailit JL, et al. Preterm neonatal morbidity and mortality by gestational age: a contemporary cohort. American journal of obstetrics and gynecology. 2016 ;215(1):103.

2. Chen KH, Chen IC, Yang YC, et al. The trends and associated factors of preterm deliveries from 2001 to 2011 in Taiwan. Medicine. 2019 ;98(13).

3. Shabaan OM, Hassanin IM, Makhlouf AM, et al. Vaginal progesterone for prevention of preterm delivery in women with twin pregnancy: a randomized controlled trial. Facts, views \& vision in ObGyn. 2018; 10(2):93.

4. Armanian AM, Barekatain B, Sohrabi F, et al. The prevalence of complications of prematurity among 1000 newborns in Isfahan, Iran. Advanced Biomedical Research. 2019; 8(2): 36-47.

5. Currell R, Harlow F, Callow L, et al. Home uterine monitoring for detecting preterm labour. The Cochrane Database of Systematic Reviews. 2017; (2).

6. Van Zijl MD, Koullali B, Mol BW, et al. Prevention of preterm delivery: current challenges and future prospects. International journal of women's health. 2016;8:633.

7. Abdelaziz MH. Oral Versus Vaginal Progesterone In Preterm Labor. Evidence Based Women's Health Journal. 2017 ; 7(4):141-9.

8. Borna, S. Progesterone effect on fetal Doppler velocimetry in in pregnant women with IUGR and preterm labour. Ultrasound in Obstetrics \& Gynecology. 2014 ; 44(S1), 265-6. 
9. da Fonseca EB, Bittar RE, Carvalho MH, et al. Prophylactic administration of progesterone by vaginal suppository to reduce the incidence of spontaneous preterm birth in women at increased risk: a randomized placebo-controlled doubleblind study. American journal of obstetrics and gynecology. $2003 ; 188$ (2):419-24.

10. Farine D, Mundle WR, Dodd J, et al. The use of progesterone for prevention of preterm birth. Journal of Obstetrics and Gynaecology Canada. 2008 ;30(1):67-71.

11. Dodd J, Jones L, Flenady V, et al. Prenatal administration of progesterone for preventing preterm birth in women considered to be at risk of preterm birth. Cochrane Database Syst Rev. $2013 ; 7,4947$.

12. O'brien JM, Adair CD, Lewis DF, et al. Progesterone vaginal gel for the reduction of recurrent preterm birth: primary results from a randomized, double -blind, placebo- controlled trial. Ultrasound in Obstetrics and Gynecology.2007; 30(5):687-96.

13. Tita AT and Rouse DJ. Progesterone for preterm birth prevention: an evolving intervention. American Journal of Obstetrics and Gynecology. 2009 ;200(3):219-24.

14. Farine D, Mundle WR, Dodd J, et al. The use of progesterone for prevention of preterm birth. Journal of Obstetrics and Gynaecology Canada. 2008 ;30(1):67-71.

15. Cetingoz E,Cam C, Sakallı M, et al. Progesterone effects on preterm birth in high-risk pregnancies: a randomized placebo-controlled trial. Archives of Gynecology and Obstetrics. 2011 ;283(3):423-9.

16. De Franco E, O'brien J, Adair C, et al. Vaginal progesterone is associated with a decrease in risk for early preterm birth and improved neonatal outcome in women with a short cervix: a secondary analysis from a randomized, double blind, placebo -Ucltornastrooullednd irnial.

Obstetrics \& Gynecology. 2007 ; 30(5), 697-705.

17. Barda G, Ben-Haroush A, Barkat J, et al. Effect of vaginal progesterone, administrated to prevent preterm birth, on impedance to blood flow in fetal and uterine circulation. Ultrasound Obstet Gynecol . 2010 ; 36:743-8.

18. Rebarber A, Istwan NB, Russo-Stieglitz K, et al . Increased incidence of gestational diabetes in women receiving prophylactic 17alphahydroxyprogesterone caproate for prevention of recurrent preterm delivery. Diabetes Care . 2007 ; 30(9): 2277-80. 